\title{
François Pluvinage en la memoria
}

\author{
Luis Moreno Armella ${ }^{1}$
}

En agosto de 1978 en Santiago de Compostela se conocieron el profesor François Pluvinage y el profesor Eugenio Filloy. Ese encuentro marcó el inicio de una relación que François iba a sostener con nuestro Departamento de Matemática Educativa de manera permanente. Desde entonces, esa amistad no hizo nada distinto a crecer y profundizar las raíces de un árbol que ha dado muchos frutos. François fue siempre una suerte para nuestros estudiantes a

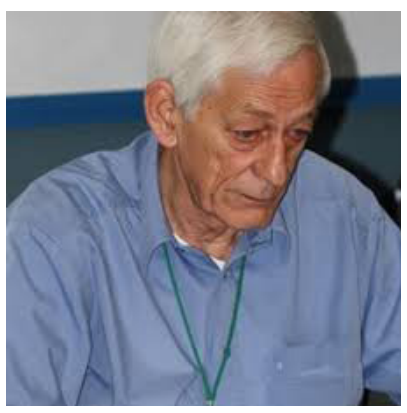
lo largo de todo ese tiempo y, sin duda, para nosotros todos. No solamente por su profundidad académica sino por su bonhomía, su trato amable y su voz de trueno que llenaba los espacios en los que se encontraba. Desde un primer momento fue tangible que su presencia iba a garantizar un diálogo permanente con él y su cultura.

Por allá en 1986 estuvo en el departamento durante todo un año sabático; eran entonces los primeros años del doctorado en nuestro departamento y su trabajo ayudó no solo a señalar la ruta sino a hacerla transitable. Nos enseñó métodos de análisis de datos novedosos que contribuyeron a consolidar investigaciones doctorales, pero a mi juicio, lo más importante fue su ejemplo de tenacidad a fuego lento y la ausencia de prejuicios para escuchar a todos. Eso

1 Departamento de Matemática Educativa, México, Imorenoa@cinvestav.mx 
se llama madurez a secas. Una cuenta rápida de su paso entre nosotros indica que ha sido profesor titular del departamento, que nos representó académicamente en más de 25 eventos, tanto nacionales como internacionales, representándonos con una dedicación, con una convicción que nunca sorprendió a ninguno de quienes lo conocimos largamente. A nombre del departamento estuvo en Canadá, en Suiza, en Colombia, en Chile recientemente, hasta en Francia, eso sí, ejerciendo de embajador nuestro y no al contrario. Desde luego, describir la tierra fértil que ha dejado tras sus pasos sería casi interminable. A los colegas de aquí, su casa, y también a egresadas y egresados nuestros les facilitó, primeramente, su brújula y más adelante, ciudadano de su tiempo, su GPS para trazar un mapa en el complejo mundo de la investigación. Tejió relaciones académicas permanentes; hoy esos colegas se han acercado para dejar un testimonio de cuan decisivo ha sido en sus trayectorias haberle encontrado siempre con los brazos abiertos, dispuesto a escuchar, a argumentar, a conciliar y contradecir pero siempre desde el respeto hacia quien estaba frente a él.

¿Dónde no dejó una huella? ¿Dónde no estuvo? México ha sido su casa. Su presencia será permanente en muchos centros educativos pues concibió su permanencia en nuestra institución como su puerto, no como su encierro. François no fue un viajero, fue sobre todo un sembrador. Cuando aún hoy paso frente a la que fue durante mucho tiempo su oficina, siempre con la puerta entornada, lo recuerdo trabajando sobre su máquina y aquello me lleva a unas palabras del escultor Auguste Rodin: "Sólo se encuentra la belleza trabajando". Para él, tendremos siempre buenas palabras, para agradecerle su trabajo de tantos años, agradecerle la huella que día a día dejó profunda en nuestro surco, que desde hace tanto tiempo hizo suyo. Es difícil condensar en pocas líneas su tiempo entre nosotros, más difícil aún dispuestos como estamos, a afirmar entre nosotros con las razones de Pascal, su presencia de siempre. Adiós al maestro, al pensador, al amigo.

LUIS MORENO ARMELLA

Domicilio postal: Av. Instituto Politécnico Nacional 2508

Col. San Pedro Zacatenco,

Alcaldía Gustavo A. Madero, C.P. 07360

Teléfonos: $\quad$ (52)+(55)-57-47-38-15 